\title{
Crystal structure of the potato leafroll virus coat protein and implications for viral assembly
}

Myfanwy C. Adams ${ }^{1}$, Carl J. Schiltz ${ }^{1 \dagger}$, Michelle L. Heck ${ }^{2,3}$, and Joshua S. Chappie ${ }^{1, *}$

${ }^{1}$ Department of Molecular Medicine, Cornell University, Ithaca, NY, 14853, USA.

${ }^{2}$ Department of Plant Pathology and Plant-Microbe Biology, Cornell University, Ithaca, NY 14853, USA.

${ }^{3}$ Boyce Thompson Institute, Ithaca, NY 14853, USA.

* To whom correspondence should be addressed. Tel: +1 (607) 253-3654; Fax: +1 (607) 253-3659;

Email: chappie@cornell.edu

$\dagger$ Present address: Department of Biological Sciences, Vanderbilt University, Nashville, TN 37232, USA

Running title: Crystal structure of the PLRV coat protein

Key words: icosahedral virus, quasi-equivalence, viral assembly, capsid, plant virus, potato leafroll virus

Manuscript format: Protein Structure Report

Manuscript includes 2 tables and 2 figures:

Table 1. X-ray data collection and refinement statistics for PLRV CP.

Table 2. Overall RMSD values calculated from superposition of PLRV CP subunits.

Figure 1. Construct design and coat protein monomer structure.

Figure 2. The coat protein asymmetric unit in the context of crystal packing reveals characteristic icosahedral symmetry. 


\begin{abstract}
Luteoviruses, poleroviruses, and enamoviruses are insect-transmitted, agricultural pathogens that infect a wide array of staple food crops. Previous cryo-electron microscopy studies of virus-like particles indicate that luteovirid viral capsids are built from a structural coat protein that organizes with $\mathrm{T}=3$ icosahedral symmetry. Here we present the crystal structure of a truncated version of the coat protein monomer from potato leafroll virus at $1.57-\AA$ resolution. In the crystal lattice, monomers pack into flat sheets that preserve the two-fold and three-fold axes of icosahedral symmetry and show minimal structural deviations when compared to the full-length subunits of the assembled virus-like particle. These observations have important implications in viral assembly and maturation, suggesting that the CP N-terminus and its interactions with RNA serve as a key driver for generating capsid curvature.
\end{abstract}




\section{Introduction}

Viral capsids exhibiting icosahedral symmetry are constructed with 60 identical subunits arranged around 12 vertices with 5-fold rotational symmetry, 20 triangular faces with 3-fold symmetry, and 30 edges with 2-fold symmetry (Sevvana et al., 2021). Icosahedral viruses containing more than 60 subunits follow the principles of quasi-equivalence (Caspar and Klug, 1962), wherein identical subunits form both hexamer and pentamer morphological units that serve as the building blocks for the quasi-equivalent viral particle (Johnson, 1996). The triangulation number $T\left(T=h^{2}+h k+k^{2}\right.$, where $h$ and $k$ are integers) relates how pentamers can be inserted into a hexagonal lattice to produce an enclosed icosahedron and defines the discrete geometric subdivisions of the triangular face needed to accommodate an increased number of subunits (Rossmann, 2013). By these rules, capsids containing $60 T$ subunits will arrange as 12 pentamers and $10(T-1)$ hexamers with the underlying icosahedral asymmetric unit containing $T$ subunits that are quasi-equivalent to each other (Johnson and Speir, 1997; Prasad and Schmid, 2011). A T=3 virus therefore contains 180 total subunits $(60 \times 3)$ with three quasi-equivalent monomers forming each triangular face of the icosahedron.

Luteoviruses, poleroviruses, and enamoviruses (collectively referred to as 'luteovirids') are economically important agricultural pathogens that devastate many staple food crops (Ali et al., 2014). Luteovirids replicate exclusively in plant hosts and are phloem-limited, relying on particular species of phloem-feeding insects for efficient transmission in a circulative manner that involves movement across and within specific insect tissues (Gray et al., 2014; Gray and Gildow, 2003; Whitfield et al., 2015). These viruses contain a single-stranded, positive sense RNA genome that encodes two major structural proteins (Miller et al., 1995): a coat protein (CP) and a minor readthrough protein (RTP) that is translated via stochastic ribosomal readthrough of the CP stop codon (Brault et al., 1995; Cheng et al., 1994; Dong et al., 1998; Filichkin et al., 1994) (Figure 1A). The readthrough domain (RTD) that is added to the $\mathrm{CP}$ is not required for virion assembly or infection (Filichkin et al., 1994; Reutenauer et al., 1993) but plays a critical role in viral uptake and transmission by aphids (Bruyère et al., 1997; Chay et al., 1996; Gildow et al., 2000; Peter et al., 2008; Reinbold et al., 2001) and has been implicated in the long-range movement (Boissinot et al., 2014) and phloem-limitation (Peter et al., 2009) of the virus in plants. Cryo-electron microscopy (cryo-EM) characterization of polerovirus virus-like particles (VLPs) lacking the RTD confirmed that luteovirid capsids assemble with $\mathrm{T}=3$ icosahedral symmetry and identified the key 
interfaces and contacts between CP subunits that maintain the structural integrity of the virion (Byrne et al., 2019). Here we present the crystal structure of a truncated version of the coat protein monomer from potato leafroll virus $\left(\mathrm{PLRV}^{68-208}\right)$ at $1.57-\AA$ resolution. In the crystal lattice, PLRV ${ }^{68-208}$ packs into flat sheets that are stabilized exclusively by hexameric interactions. This organization preserves the two-fold and three-fold axes of icosahedral symmetry but lacks the curvature necessary to generate enclosed VLPs. Structural comparison between PLRV ${ }^{68-208}$ and VLP subunits shows minimal structural differences across the CP monomer core, implicating the truncated N-terminus and its interactions with RNA as an important driver of viral assembly and maturation.

\section{Materials and methods}

\subsection{Cloning, expression, and purification of PLRV $V^{68-208}$}

DNA encoding PLRV minimal capsid domain (residues 68-208) was cloned from an infective PLRV isolate and inserted into pCAV4, a modified T7 expression vector that introduced an Nterminal 6xHis-NusA tag followed by a HRV 3C protease site upstream of the inserted sequence. Constructs were transformed into BL21(DE3) cells, grown at $37^{\circ} \mathrm{C}$ in Terrific Broth to an $\mathrm{OD}_{600}$ of 0.7-0.9, and then induced with $0.3 \mathrm{mM}$ IPTG overnight at $19^{\circ} \mathrm{C}$. Cells were pelleted and resuspended in nickel loading buffer (20 mM HEPES pH 7.5, $500 \mathrm{mM} \mathrm{NaCl}, 30 \mathrm{mM}$ imidazole, $5 \%$ glycerol (v:v), and $5 \mathrm{mM} \beta$-mercaptoethanol) supplemented with $0.5 \mathrm{mg}$ DNAse, $10 \mathrm{mM}$ $\mathrm{MgCl}_{2}, 1 \mathrm{mM}$ PMSF, and a Roche complete protease inhibitor cocktail tablet. Lysozyme was added to a concentration of $1 \mathrm{mg} / \mathrm{ml}$ and the mixture was incubated for 10 minutes rocking at $4^{\circ} \mathrm{C}$. Cells were disrupted by sonication and the lysate was cleared via centrifugation at $13000 \mathrm{rpm}$ (19 $685 \mathrm{~g}$ ) for 30 minutes at $4^{\circ} \mathrm{C}$. The supernatant was filtered, loaded onto a $5 \mathrm{ml}$ HiTrap chelating column charged with $\mathrm{NiSO}_{4}$, and then washed with nickel loading buffer. PLRV ${ }^{68-208}$ was eluted by an imidazole gradient from $30 \mathrm{mM}$ to $500 \mathrm{mM}$. HRV $3 \mathrm{C}$ protease was added to the pooled fractions, which were subsequently dialyzed overnight at $4^{\circ} \mathrm{C}$ against $\mathrm{S}$ buffer $(20 \mathrm{mM}$ HEPES $\mathrm{pH}$ 7.5, $50 \mathrm{mM} \mathrm{NaCl}, 1 \mathrm{mM}$ EDTA, 5\% glycerol (v:v), and $1 \mathrm{mM}$ DTT). Significant precipitation occurred during dialysis; however, uncut NusA-PLRV ${ }^{68-208}$ constituted the vast majority of the insoluble fraction. The clarified protein sample was applied to a $5 \mathrm{ml}$ HiTrap S column equilibrated with $\mathrm{S}$ buffer. The sample was washed with $\mathrm{S}$ buffer and eluted with a $\mathrm{NaCl}$ gradient from $50 \mathrm{mM}$ to $500 \mathrm{mM}$ over 12 column volumes. Peak S column fractions were pooled, concentrated, and 
injected onto a Superdex 75 10/300 GL sizing column equilibrated in 20 mM HEPES pH 7.5, 150 $\mathrm{mM} \mathrm{KCl}$, and $1 \mathrm{mM}$ DTT. The protein was concentrated to $10-20 \mathrm{mg} / \mathrm{ml}$, flash frozen in liquid nitrogen, and stored at $-80^{\circ} \mathrm{C}$.

\subsection{Crystallization, X-ray data collection, and structure determination}

PLRV ${ }^{68-208}(6-10 \mathrm{mg} / \mathrm{mL})$ was mixed in a 1:1 ratio with 0.1 M Bis-Tris Propane $\mathrm{pH}$ 7.7, 26\% PEG 3350, and 0.1 M NaBr. The highest quality crystals were obtained using sitting drop vapour diffusion with a drop size of $2 \mathrm{uL}$ and reservoir volume of $65 \mathrm{uL}$ at $20^{\circ} \mathrm{C}$. Samples were cryoprotected by transferring the crystal directly to Parabar 10312 (Hampton Research) prior to freezing in liquid nitrogen. Crystals were of the space group P1 with unit cell dimensions a $=36.86$ $\AA, b=67.49 \AA, c=75.88 \AA$ and $\alpha=79.66^{\circ}, \beta=76.21^{\circ}, \gamma=81.64^{\circ}$. Data were collected remotely on the tuneable NE-CAT 24-ID-C beamline at the Advanced Photon Source at the selenium edge energy at $12.663 \mathrm{kEv}$ (Table 1). Data were integrated and scaled using XDS (Kabsch, 2010) and AIMLESS (Evans and Murshudov, 2013) via the NE-CAT RAPD pipeline. The structure was solved by molecular replacement using PHASER (McCoy and Read, 2010) and a monomer from the cryo-EM structure of the PLRV VLP (PDB: 6SCO) as the search model. Further model building and refinement was carried out manually in COOT (Emsley et al., 2010) and PHENIX (Liebschner et al., 2019), respectively. The final model was refined to 1.57-Å resolution with $\mathrm{R}_{\text {work }} / \mathrm{R}_{\text {free }}=0.1792 / 0.2281$ (Table 1 ) and contained six identical molecules in the asymmetric unit: chains A-F, 68-208. All structural models were rendered with Pymol (Schrodinger).

\section{Results and discussion}

\subsection{Structural fold of truncated PLRV $V^{68-208}$}

PLRV is phloem limited, making it difficult to obtain sufficient quantities of mature, infectious virions from natural sources for comprehensive structural studies. We instead designed a soluble, PLRV CP construct (PLRV ${ }^{68-208}$ ) that could be expressed in E. coli and purified in milligram quantities. The domain boundaries of this construct were chosen based on disorder prediction (Erdős and Dosztányi, 2020), truncating the flexible, arginine-rich N-terminus (residues 1-67) that ordinarily interacts with viral RNA (Figure 1A). Purified PLRV ${ }^{68-208}$ exists as a monodispersed, unassembled monomer in solution and produced small, needle-like crystals that routinely diffracted to $\sim 1-2 \AA$. Crystals were of the space group P1 with six molecules in the asymmetric 
unit. The structure was solved by molecular replacement using a monomer from the PLRV VLP cryo-EM structure (PDB: 6SCO) as a search model. The final model was refined to 1.57- $\AA$ resolution with $\mathrm{R}_{\text {work }}$ and $\mathrm{R}_{\text {free }}$ values of $0.1792 / 0.2281$ (Table 1 ).

The truncated PLRV ${ }^{68-208}$ monomer adopts a jelly-roll fold composed of two antiparallel beta sheets - topologically ordered $\beta \mathrm{B}-\beta \mathrm{I}-\beta \mathrm{D}-\beta \mathrm{G}$ and $\beta \mathrm{F}-\beta \mathrm{E}-\beta \mathrm{H}-\beta \mathrm{C}$ (Rossmann and Johnson, 1989) - that sandwich together and are flanked by two $\alpha$-helices (Figure 1B-C). Superposition shows good overall structural agreement between PLRV $68-208$ and the full-length CP monomer that make up the asymmetric unit of the PLRV VLP cryo-EM structure (Figure 1D), with overall RMSDs across backbone atoms on the order $\sim 0.5 \AA$ when each chain is compared (Table 2 ). The main structural variations occur in the positions of the $\beta \mathrm{D}-\beta \mathrm{E}, \beta \mathrm{E}-\beta \mathrm{F}$, and $\beta \mathrm{H}-\beta \mathrm{I}$ loops (Figure 1D). This indicates that the core CP fold remains largely unaffected by the underlying lattice organization.

\subsection{Crystal packing demonstrates innate preference for elements of icosahedral symmetry}

PLRV 68-208 monomers pack in layers of flat sheets that stack on top of one another within the crystal lattice (Figure 2A). The crystallographic asymmetric unit spans two of these layers, with three molecules localized to each plane in different orientations (Figure 2A-B). Within a single sheet, the protein monomers form an ordered array that contains two-fold, three-fold, and six-fold non-crystallographic symmetry (Figure 2C). This organization recapitulates the subunit interfaces found within the assembled capsid of PLRV VLPs as well as the two-fold and three-fold icosahedral symmetry axes (Figure 2D). VLP assembly with a five-fold axis in place of a six-fold axis imposes constraints that induce significant curvature, allowing closure of the icosahedron (Figure 2E). Direct comparison of the planar (Figure 2C) and icosahedral (Figure 2D) asymmetric units shows that a slight downward rotation of the $\mathrm{B}$ and $\mathrm{C}$ subunits and $\sim 9^{\circ}$ upward tilt of the $\mathrm{A}$ subunit accompanies the underlying symmetry transition from flat sheet to mature capsid (Figure 2F).

\subsection{Implications for viral capsid assembly}

In developing the conceptual framework of quasi-equivalence, Caspar and Klug argued that (i) the inter-subunit bonding energy serves as the driving force for assembly, (ii) a closed shell maximizes the number of bonds between subunits, and (iii) introduction of pentamers is required to achieve 
the natural curvature needed for shell closure, even if hexamers are intrinsically stable enough to be formed preferentially (Caspar and Klug, 1962). The distinct PLRV CP assemblies captured by X-ray crystallography and cryo-EM exemplify these principles. PLRV ${ }^{68-208}$ exclusively forms hexameric interactions within the crystal lattice and thus remains organized in planar sheets. In contrast, assembly of full-length CP monomers in planta efficiently incorporates pentamers, leading to stable VLPs. These structural changes occur with minimal distortions to the overall fold and without significant perturbations to the primary intersubunit interactions, providing experimental support for Caspar and Klug's theoretical descriptions.

The PLRV VLPs used for cryo-EM studies were generated by transiently expressing the full-length CP in Nicotiana benthamiana following agroinfiltration (Byrne et al., 2019). The resulting particles contain an interior amorphous density that likely consists of the N-terminal domains and/or packaged RNA (Byrne et al., 2019). Our attempts to express the full-length PLRV CP in E. coli yielded only unfolded aggregates. Luteovirid VLPs have also been produced using baculovirus expression systems in insect cells (Gildow et al., 2000; Lamb et al., 1996; Sivakumar et al., 2009; Tian et al., 1995). For PLRV, the native CP was insoluble in Sf9 cells but could be coaxed to form VLPs when an extended histidine tag was added at the N-terminus (Gildow et al., 2000; Lamb et al., 1996). His-tagged pea enation mosaic virus 1 (PEMV) CP constructs expressed in Sf21 cells formed VLPs that were heterogeneous in size and contained baculoviral mRNA (Sivakumar et al., 2009). Non-tagged PEMV VLPs could not be purified (Sivakumar et al., 2009), however, mirroring the behavior of baculovirus-derived beet western yellow virus VLPs (Tian et al., 1995). These observations suggest that accessory factors in host plants likely play a critical role in the proper assembly of luteovirid capsids from native CP subunits. Cross-linking coupled to high resolution mass spectrometry previously identified plant chaperones that interact with the PLRV CP and may play a role in this process (DeBlasio et al., 2016).

The $\mathrm{T}=3$ icosahedral symmetry of PLRV capsids dictates that the $\mathrm{A}, \mathrm{B}$, and $\mathrm{C}$ subunits within the icosahedral asymmetric unit (Figure 2D) are quasi-equivalent despite deriving from identical gene products. In many $\mathrm{T}=3$ viruses, the flexible $\mathrm{N}$-terminal portion of the capsid protein mediates conformational differences that facilitate non-equivalent interactions (Prasad and Schmid, 2011), be it through order-to-disorder transitions (Abad-Zapatero et al., 1980; Harrison et al., 1978; Hogle et al., 1986; Prasad et al., 1999), direct interactions with genomic RNA (Fisher and Johnson, 1993; Makino et al., 2013), or residue-specific conformational changes (Chen et al., 
2006; Ossiboff et al., 2010). Mutagenesis and/or deletion of this N-terminal region often disrupts capsid assembly (Bertolotti-Ciarlet et al., 2002; Dong et al., 1998; Wikoff and Johnson, 1999), underscoring its importance in virion stability and icosahedral quasi-equivalent switching. We speculate that the CP N-terminus plays a similar regulatory role in PLRV based on PLRV ${ }^{68-208}$ 's inability to form closed capsids and the non-symmetric cryo-EM density present in the interior of the PLRV VLPs, which would be occupied by the residues removed from the truncated CP construct and/or scavenged RNA that associates with them.

\subsection{Concluding remarks}

Understanding viral assembly is critical for the development of new strategies to mitigate luteovirid transmission and subsequent crop loss. Our work shows that crystallography is a viable approach to elucidate the structural geometry and symmetry interactions of other luteovirids when the formation of VLPs and/or isolation of stable, mature virions is not possible. The PLRV ${ }^{68-208}$ crystal structure not only affords a high-resolution snapshot of the PLRV CP monomer but also shows a potential intermediate stage of capsid folding. Future in vitro studies examining $\mathrm{CP}$ assembly and the effects of viral RNA will be necessary to define the exact mechanism and kinetics of PLRV maturation. The PLRV CP assemblies described and compared in this work will help in modelling these pathways.

\section{Accession numbers}

The atomic coordinates and structure factors for the truncated potato leafroll virus coat protein (residues 68-208) have been deposited in the Protein Data Bank (http://www.rcsb.org) under the PDB code 7RLM.

\section{CRediT authorship contribution statement}

Myfanwy C. Adams: Conceptualization, Methodology, Validation, Investigation, Writing original draft, Visualization. Carl J. Schiltz: Conceptualization, Methodology, Validation, Investigation, Visualization. Michelle L. Heck: Conceptualization, Methodology, Validation, Investigation, Writing - original draft, Supervision, Funding acquisition. Joshua S. Chappie: Conceptualization, Methodology, Validation, Investigation, Writing - original draft, Visualization, Supervision, Funding acquisition. 


\section{Declaration of competing interest}

The authors declare that they have no known competing financial interests or personal relationships that could have appeared to influence the work reported in this paper.

\section{Acknowledgements}

We thank the Northeastern Collaborative Access Team (NE-CAT) beamline staff at the Advanced Photon Source (APS) for assistance with remote X-ray data collection. This work was supported by USDA Agricultural Research grant 2019-05200 (to M.L.H. and J.S.C) and is based upon research conducted at the Northeastern Collaborative Access Team (NE-CAT) beamlines under GUP-62147 (PI: J.S.C.). NE-CAT is funded by the National Institute of General Medical Sciences from the National Institutes of Health (P30 GM124165). The Pilatus 6M detector on 24-ID-C beam line is funded by a NIH-ORIP HEI grant (S10 RR029205). This research used resources of the Advanced Photon Source, a U.S. Department of Energy (DOE) Office of Science User Facility operated for the DOE Office of Science by Argonne National Laboratory under Contract No. DEAC02-06CH11357. J.S.C. is a Meinig Family Investigator in the Life Sciences. M.C.A. is supported by a NIFA predoctoral fellowship (2020-67034-31750). USDA is an equal opportunity provider and employer. 


\section{REFERENCES}

Abad-Zapatero, C., Abdel-Meguid, S.S., Johnson, J.E., Leslie, A.G.W., Rayment, I., Rossmann, M.G., Suck, D., Tsukihara, T., 1980. Structure of southern bean mosaic virus at $2.8 \AA$ resolution. Nature 286, 33-39.

Ali, M., Hameed, S., Tahir, M., 2014. Luteovirus: insights into pathogenicity. Arch Virol 159, 2853-2860.

Bertolotti-Ciarlet, A., White, L.J., Chen, R., Prasad, B.V.V., Estes, M.K., 2002. Structural Requirements for the Assembly of Norwalk Virus-Like Particles. J Virol 76, 4044-4055.

Boissinot, S., Erdinger, M., Monsion, B., Ziegler-Graff, V., Brault, V., 2014. Both Structural and Non-Structural Forms of the Readthrough Protein of Cucurbit aphid-borne yellows virus Are Essential for Efficient Systemic Infection of Plants. Plos One 9, e93448.

Brault, V., Heuvel, J.F., Verbeek, M., Ziegler-Graff, V., Reutenauer, A., Herrbach, E., Garaud, J.C., Guilley, H., Richards, K., Jonard, G., 1995. Aphid transmission of beet western yellows luteovirus requires the minor capsid read-through protein P74. Embo J 14, 650-659.

Bruyère, A., Brault, V., Ziegler-Graff, V., Simonis, M.-T., Heuvel, J.F.J.M.V. den, Richards, K., Guilley, H., Jonard, G., Herrbach, E., 1997. Effects of Mutations in the Beet Western Yellows Virus Readthrough Protein on Its Expression and Packaging and on Virus Accumulation, Symptoms, and Aphid Transmission. Virology 230, 323-334.

Byrne, M.J., Steele, J.F.C., Hesketh, E.L., Walden, M., Thompson, R.F., Lomonossoff, G.P., Ranson, N.A., 2019. Combining Transient Expression and Cryo-EM to Obtain HighResolution Structures of Luteovirid Particles. Structure 27, 1761-1770.e3.

Caspar, D.L.D., Klug, A., 1962. Physical Principles in the Construction of Regular Viruses. Cold Spring Harb Sym 27, 1-24.

Chay, C.A., Gunasinge, U.B., Dinesh-Kumar, S.P., Miller, W.A., Gray, S.M., 1996. Aphid Transmission and Systemic Plant Infection Determinants of Barley Yellow Dwarf LuteovirusPAV are Contained in the Coat Protein Readthrough Domain and 17-kDa Protein, Respectively. Virology 219, 57-65.

Chen, R., Neill, J.D., Estes, M.K., Prasad, B.V.V., 2006. X-ray structure of a native calicivirus: Structural insights into antigenic diversity and host specificity. Proc National Acad Sci 103,

Cheng, S.-L., Domier, L.L., D’Arcy, C.J., 1994. Detection of the Readthrough Protein of Barley Yellow Dwarf Virus. Virology 202, 1003-1006. 
DeBlasio, S.L., Chavez, J.D., Alexander, M.M., Ramsey, J., Eng, J.K., Mahoney, J., Gray, S.M., Bruce, J.E., Cilia, M., 2016. Visualization of Host-Polerovirus Interaction Topologies Using Protein Interaction Reporter Technology. J Virol 90, 1973-1987.

Dong, X.F., Natarajan, P., Tihova, M., Johnson, J.E., Schneemann, A., 1998. Particle Polymorphism Caused by Deletion of a Peptide Molecular Switch in a Quasiequivalent Icosahedral Virus. J Virol 72, 6024-6033.

Emsley, P., Lohkamp, B., Scott, W.G., Cowtan, K., 2010. Features and development of Coot. Acta Crystallogr Sect D Biological Crystallogr 66, 486-501.

Erdős, G., Dosztányi, Z., 2020. Analyzing Protein Disorder with IUPred2A. Curr Protoc Bioinform 70, e99.

Evans, P.R., Murshudov, G.N., 2013. How good are my data and what is the resolution? Acta Crystallogr Sect D Biological Crystallogr 69, 1204-1214.

Filichkin, S.A., Lister, R.M., McGrath, P.F., Young, M.J., 1994. In Vivo Expression and Mutational Analysis of the Barley Yellow Dwarf Virus Readthrough Gene. Virology 205, 290-299.

Fisher, A.J., Johnson, J.E., 1993. Ordered duplex RNA controls capsid architecture in an icosahedral animal virus. Nature 361, 176-179.

Gildow, F.E., Reavy, B., Mayo, M.A., Duncan, G.H., Woodford, J.A.T., Lamb, J.W., Hay, R.T., 2000. Aphid Acquisition and Cellular Transport of Potato leafroll virus -like Particles Lacking P5 Readthrough Protein. Phytopathology 90, 1153-1161.

Gray, S., Cilia, M., Ghanim, M., 2014. Chapter Four Circulative, "Nonpropagative” Virus Transmission An Orchestra of Virus-, Insect-, and Plant-Derived Instruments. Adv Virus Res 89, 141-199.

Gray, S., Gildow, F.E., 2003. Luteovirus-aphid interactions. Annu Rev Phytopathol 41, 539-566.

Harrison, S.C., Olson, A.J., Schutt, C.E., Winkler, F.K., Bricogne, G., 1978. Tomato bushy stunt virus at $2.9 \AA$ Å resolution. Nature 276, 368-373.

Hogle, J.M., Maeda, A., Harrison, S.C., 1986. Structure and assembly of turnip crinkle virus I. X-ray crystallographic structure analysis at $3.2 \AA$ resolution. J Mol Biol 191, 625-638.

Johnson, J.E., 1996. Functional implications of protein-protein interactions in icosahedral viruses. Proc National Acad Sci 93, 27-33.

Johnson, J.E., Speir, J.A., 1997. Quasi-equivalent viruses: a paradigm for protein assemblies11Edited by T. Richmond. J Mol Biol 269, 665-675. 
Kabsch, W., 2010. XDS. Acta Crystallogr Sect D Biological Crystallogr 66, 125-132.

Lamb, J.W., Duncan, G.H., Reavy, B., Gildow, F.E., Mayo, M.A., Hay, R.T., 1996. Assembly of virus-like particles in insect cells infected with a baculovirus containing a modified coat protein gene of potato leafroll luteovirus. J Gen Virol 77, 1349-1358.

Liebschner, D., Afonine, P.V., Baker, M.L., Bunkóczi, G., Chen, V.B., Croll, T.I., Hintze, B., Hung, L.-W., Jain, S., McCoy, A.J., Moriarty, N.W., Oeffner, R.D., Poon, B.K., Prisant, M.G., Read, R.J., Richardson, J.S., Richardson, D.C., Sammito, M.D., Sobolev, O.V., Stockwell, D.H., Terwilliger, T.C., Urzhumtsev, A.G., Videau, L.L., Williams, C.J., Adams, P.D., 2019. Macromolecular structure determination using X-rays, neutrons and electrons: recent developments in Phenix. Acta Crystallogr Sect D 75, 861-877.

Makino, D.L., Larson, S.B., McPherson, A., 2013. The crystallographic structure of Panicum Mosaic Virus (PMV). J Struct Biol 181, 37-52.

McCoy, A.J., Read, R.J., 2010. Experimental phasing: best practice and pitfalls. Acta Crystallogr Sect D Biological Crystallogr 66, 458-469.

Miller, W.A., Dinesh-Kumar, S.P., Paul, C.P., 1995. Luteovirus Gene Expression. Crit Rev Plant Sci 14, 179-211.

Ossiboff, R.J., Zhou, Y., Lightfoot, P.J., Prasad, B.V.V., Parker, J.S.L., 2010. Conformational Changes in the Capsid of a Calicivirus upon Interaction with Its Functional Receptor $\nabla$. J Virol 84, 5550-5564.

Peter, K.A., Gildow, F., Palukaitis, P., Gray, S.M., 2009. The C Terminus of the Polerovirus P5 Readthrough Domain Limits Virus Infection to the Phloem. J Virol 83, 5419-5429.

Peter, K.A., Liang, D., Palukaitis, P., Gray, S.M., 2008. Small deletions in the potato leafroll virus readthrough protein affect particle morphology, aphid transmission, virus movement and accumulation. J Gen Virol 89, 2037-2045.

Pettersen, E.F., Goddard, T.D., Huang, C.C., Couch, G.S., Greenblatt, D.M., Meng, E.C., Ferrin, T.E., 2004. UCSF Chimera-A visualization system for exploratory research and analysis. J Comput Chem 25, 1605-1612.

Prasad, B.V.V., Hardy, M.E., Dokland, T., Bella, J., Rossmann, M.G., Estes, M.K., 1999. X-ray Crystallographic Structure of the Norwalk Virus Capsid. Science 286, 287-290.

Prasad, B.V.V., Schmid, M.F., 2011. Viral Molecular Machines. Adv Exp Med Biol 726, 17-47.

Reinbold, C., Gildow, F.E., Herrbach, E., Ziegler-Graff, V., Gonçalves, M.C., Heuvel, J.F.J.M. van den, Brault, V., 2001. Studies on the role of the minor capsid protein in transport of Beet western yellows virus through Myzus persicae. J Gen Virol 82, 1995-2007. 
Reutenauer, A., Ziegler-Graff, V., Lot, H., Scheidecker, D., Guilley, H., Richards, K., Jonard, G., 1993. Identification of Beet Western Yellows Luteovirus Genes Implicated in Viral Replication and Particle Morphogenesis. Virology 195, 692-699.

Rossmann, M.G., 2013. Structure of viruses: a short history. Q Rev Biophys 46, 133-180.

Rossmann, M.G., Johnson, J.E., 1989. Icosahedral RNA Virus Structure. Annu Rev Biochem 58, 533-569.

Sevvana, M., Klose, T., Rossmann, M.G., 2021. Encyclopedia of Virology 257-277.

Sivakumar, S., Wang, Z., Harrison, R.L., Liu, S., Miller, W.A., Bonning, B.C., 2009. Baculovirus-expressed virus-like particles of Pea enation mosaic virus vary in size and encapsidate baculovirus mRNAs. Virus Res 139, 54-63.

Tian, T., Medina, V., Mayhew, D.E., Maeda, S., Falk, B.W., 1995. Beet Western Yellows Luteovirus Capsid Proteins Produced by Recombinant Baculoviruses Assemble into Virionlike Particles in Cells and Larvae of Bombyx mori. Virology 213, 204-212.

Whitfield, A.E., Falk, B.W., Rotenberg, D., 2015. Insect vector-mediated transmission of plant viruses. Virology 479, 278-289.

Wikoff, W.R., Johnson, J.E., 1999. Virus assembly: Imaging a molecular machine. Curr Biol 9, R296-R300. 
Table 1. X-ray data collection and refinement statistics for PLRV ${ }^{68-208}$.

\begin{tabular}{|c|c|}
\hline \multicolumn{2}{|l|}{ Data collection } \\
\hline PDB code & 7RLM \\
\hline X-ray Source & NECAT 24-ID-C \\
\hline Wavelength $(\AA)$ & 0.9791 \\
\hline Space group & $\mathrm{P} 1$ \\
\hline Unit cell & $\begin{array}{l}a=36.86, b=67.48, c=75.89 \AA \\
\alpha=79.67^{\circ}, \beta=76.22^{\circ}, \gamma=81.67^{\circ}\end{array}$ \\
\hline Resolution, $\AA^{\mathrm{a}}$ & $72.86-1.504(1.558-1.504)$ \\
\hline No. measured reflections $\mathrm{s}^{\mathrm{a}}$ & $323209(24594)$ \\
\hline No. unique reflections ${ }^{\mathrm{a}}$ & $177750(14912)$ \\
\hline Completeness $(\%)^{\mathrm{a}}$ & $89.1(46.8)$ \\
\hline Multiplicity & $3.3(1.5)$ \\
\hline $\mathrm{R}_{\text {merge }}{ }^{\mathrm{a}}$ & \begin{tabular}{|l|}
$0.072(0.868)$ \\
\end{tabular} \\
\hline Mean $I / \sigma_{I}{ }^{a}$ & $8.6(0.5)$ \\
\hline $\mathrm{CC}_{1 / 2} \mathrm{a}^{\mathrm{a}}$ & $0.997(0.315)$ \\
\hline \multicolumn{2}{|l|}{ Refinement } \\
\hline Resolution $(\AA)$ & $72.86-1.57$ \\
\hline No. relections & $90356(8750)$ \\
\hline $\mathrm{R}_{\mathrm{work}} / \mathrm{R}_{\text {free }}$ & $0.1792 / 0.2281$ \\
\hline \multicolumn{2}{|l|}{ RMSD } \\
\hline Bond lengths $(\AA)$ & 0.006 \\
\hline Bond angles $\left({ }^{\circ}\right)$ & 0.823 \\
\hline \multicolumn{2}{|l|}{ Ramachandran plot } \\
\hline Favored (\%) & 97.96 \\
\hline Allowed (\%) & 2.04 \\
\hline Outliers (\%) & 0.00 \\
\hline Average B-Factor & 26.14 \\
\hline Clash score & 5.53 \\
\hline \multicolumn{2}{|l|}{ No. Atoms } \\
\hline Macromolecule & 6643 \\
\hline Solvent & 686 \\
\hline Other ions if present? & 1 \\
\hline
\end{tabular}

${ }^{a}$ Parentheses indicate values for highest resolution shell 
Table 2. Overall RMSD values calculated from superposition of PLRV CP subunits.

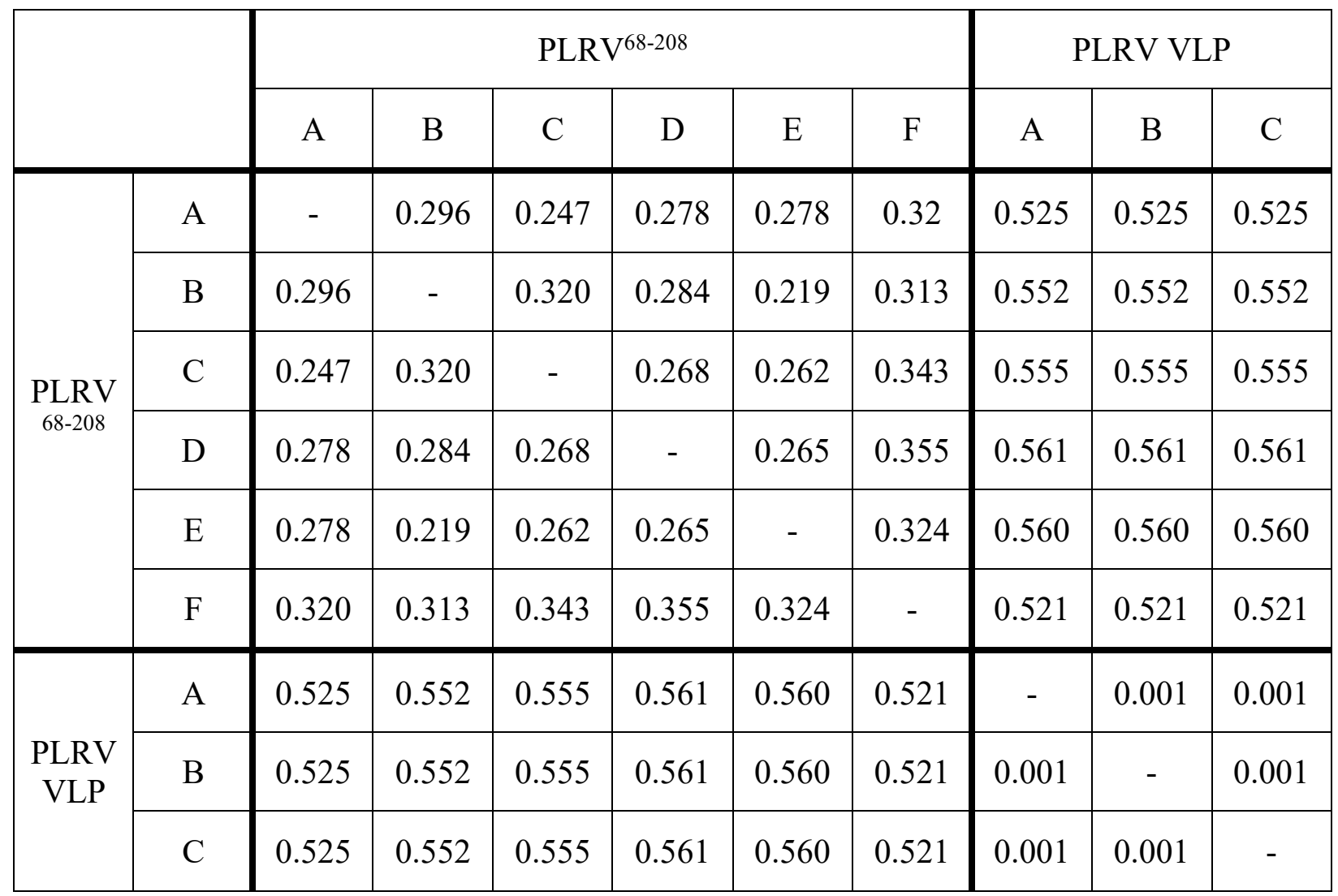

Values listed are in angstroms and represent comparison across corresponding backbone atoms. Superpositions were carried out using the matchmaker function in Chimera (Pettersen et al., 2004). 


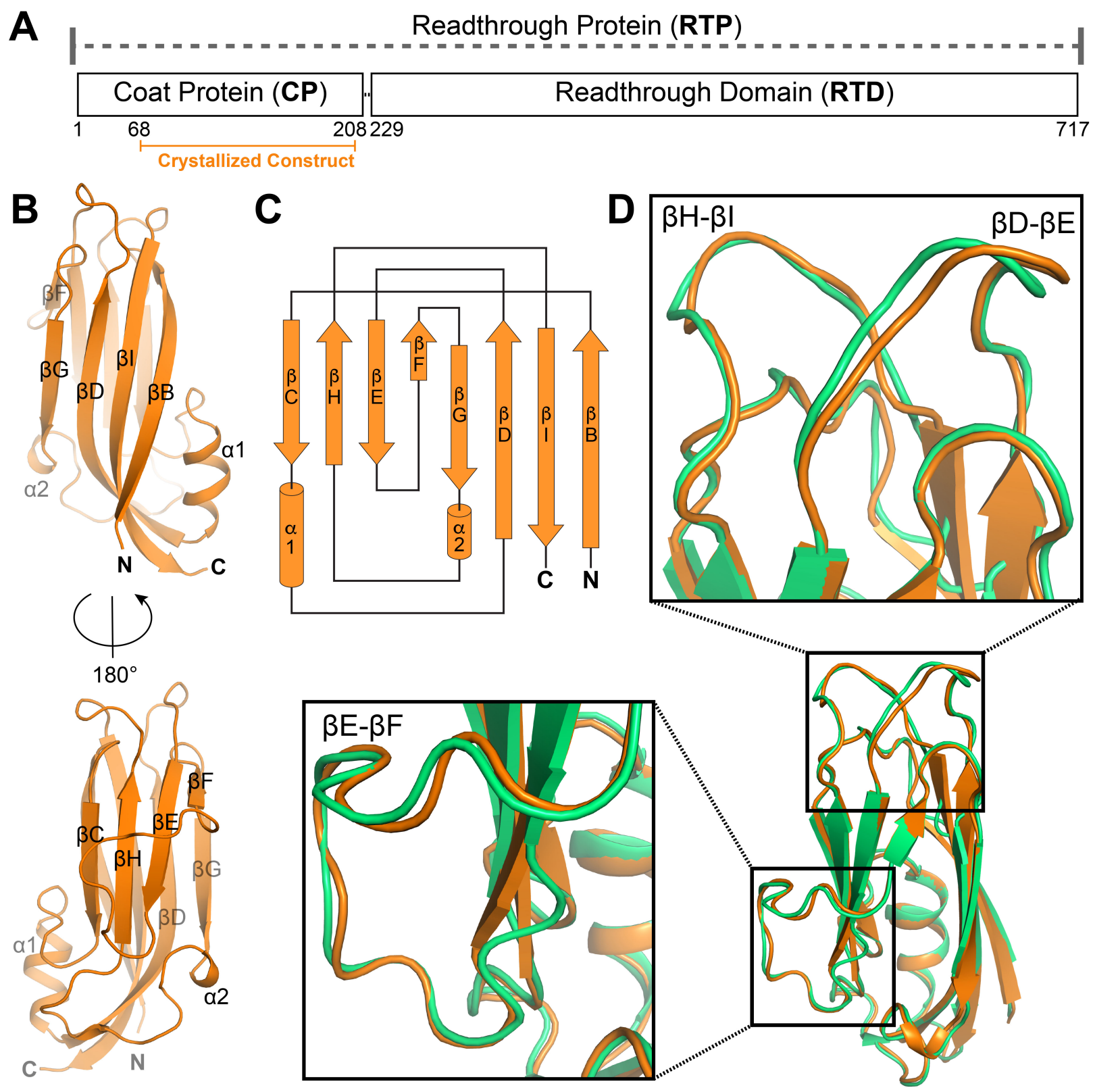

Figure 1. Structure of truncated PLRV CP monomer. A. Domain architecture of PLRV readthrough protein (RTP). Boundaries of the coat protein (CP) and readthrough domain (RTD) are labeled and numbered. Orange denotes purified fragment (PLRV ${ }^{68-208}$ ) used for crystallographic studies. B,C. Structure (B) and topology (C) of PLRV ${ }^{68-208}$ monomer. D. Superposition of PLRV ${ }^{68-208}$ chain A (orange) with full-length CP monomer derived from the cryoEM reconstruction of the PLRV virus-like particle (green, PDB: 6SCO, chain A). Black boxes highlight zoomed views of conformational differences. 


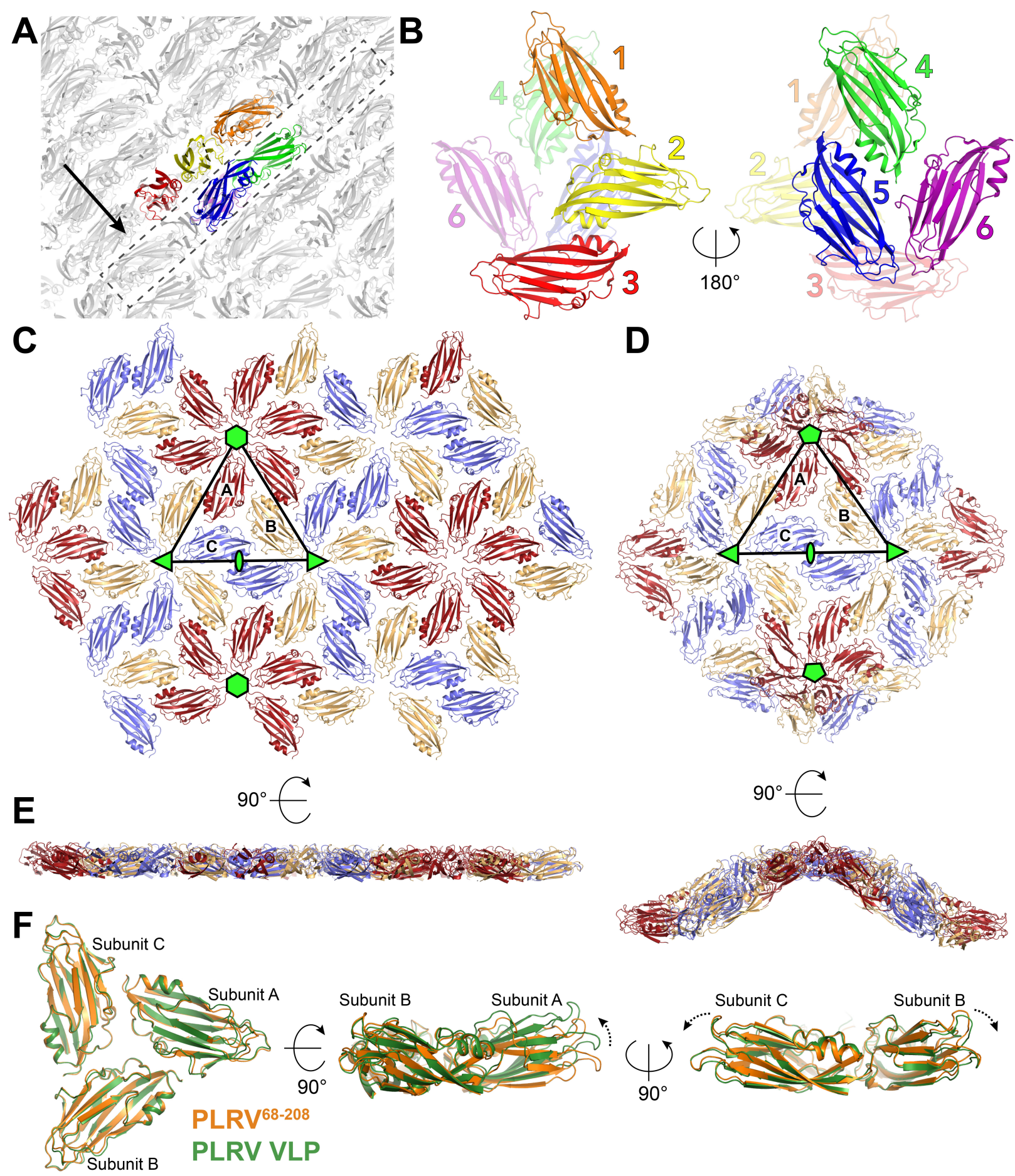

Figure 2. Crystal packing of PLRV ${ }^{68-208}$. A. CP monomers (gray) pack into planar sheets (dashed box) that are stacked on top of each other within the PLRV ${ }^{68-208}$ crystal lattice. Colored monomers indicate relative position of the asymmetric unit, which spans two sequential layers. Black arrow denotes orientation of the view in panel C. B. Spatial distribution of the six monomers in the asymmetric unit. C. Two-dimensional packing of PLRV ${ }^{68-208}$ monomers in the crystal lattice. 
Non-crystallographic two-fold (green ellipse), three-fold (green triangles), and six-fold (green hexagons) symmetry axes are marked. Monomers that comprise the planar asymmetric unit (black triangular outline) are colored red, light orange, and slate and labeled 'A', 'B', and 'C', respectively. D. T=3 icosahedral symmetry of PLRV VLPs (PDB: 6SCO). Individual subunits that constitute the icosahedral asymmetric unit (black triangular outline) are colored red, light orange, and slate and labeled 'A', 'B', and 'C', respectively. Two-fold (green ellipse), three-fold (green triangles), and five-fold (green pentagons) icosahedral symmetry axes are marked. E. Relative curvature differences between of PLRV ${ }^{68-208}$ crystal lattice (left) and PLRV VLPs (right). F. Structural superposition of the planar (orange) and icosahedral green) asymmetric units from C and D. Dashed black arrows indicate relative movements that propagate curvature in the viral capsid. 